\title{
Gasifikasi Biomassa Serbuk Gergaji Kayu Mahoni (Swietenia Mahagoni) untuk Menghasilkan Bahan Bakar Gas sebagai Sumber Energi Terbarukan
}

\author{
Astri Nurwidayati ${ }^{\mathrm{a}, 1}$, Putri Ayu Sulastri ${ }^{\mathrm{b}, 2}$, Destya Ardiyati ${ }^{\mathrm{b}, 3}$, Agus Aktawan ${ }^{\mathrm{b}, 4^{*}}$ \\ ${ }^{a}$ Departemen Teknik Kimia, Fakultas Teknik, Universitas Gadjah Mada, Jln Grafika No. 2 Kampus UGM, Yogyakarta,55281, Indonesia \\ ${ }^{\text {b }}$ Program Studi Teknik Kimia, Fakultas Teknologi Industri, Universitas Ahmad Dahlan, Jl. Ring Road Selatan, Tamanan, Banguntapan, Bantul Yogyakarta \\ 55166, Indonesia \\ ${ }^{1}$ astrinurwidayati@gmail.com; ${ }^{2}$ putrieayusulastri24@gmail.com; ${ }^{3}$ destyard31@gmail.com; ${ }^{4}$ agus.aktawan@ che.uad.ac.id \\ * corresponding author
}

ARTICLE INFO

Article history

Diterima pada May 6, 2019

Direvisi pada May 14, 2019

Disetujui pada May 14, 2019

Keywords

Biomassa

Kayu Mahoni

Gasifikasi

Syngas

\begin{abstract}
Energy cannot be separated from human life. Increased energy needs for human life that are contradictory to existing fossil fuel sources can cause an energy crisis. Biomass is an alternative energy source that is environmentally friendly, economical and renewable. Biomass energy is derived from plants such as wood, rice hulls, corn head, etc. The process of converting biomass into energy can be done in several ways. They are combustion, pyrolysis, and gasification. Gasification is a technology for converting solid materials into syngas $\left(\mathrm{CO}, \mathrm{H}_{2}\right.$, and $\mathrm{CH}_{4}$ ) which can be used as a fuel. One of the gasifiers that have been developed is a downdraft system. The solid material we use in this study is a mahogany wood powder which has a cellulose content of up to $46.8 \%$. Through this research, we can find out the effect of the variable of raw materials weight towards the time of flame, the quality of the fire, and the amount of gas produced. The gas produced was tested visually by lighting the fire and instrumentally tested using a tool called Chromatography Gas to determine the composition of the gas. The biggest yield syngas is 70,71\% with the 18,000 seconds gas release time on the variable of mahogany wood powder weight of 3500 grams. The highest $\mathrm{CH}_{4}$ and $\mathrm{CO}$ Gas concentrations were $1,868 \%$ and $15.902 \%$ on the variable of 3,500 gram mahogany powder weight. While the highest concentration of $\mathrm{H} 2$ gas is $20.965 \%$ produced with the variable of 2,500 gram mahogany powder weight. The results of this study indicate that the more feed in the gasifier, the greater the number and composition of syngas and the longer the gas release time.
\end{abstract}

This is an open access article under the CC-BY-SA license

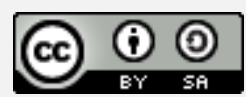

\section{Pendahuluan}

Menipisnya cadangan bahan bakar fosil dan meningkatnya populasi manusia sangat kontradiktif dengan kebutuhan energi bagi kelangsungan hidup manusia. Saat ini kebutuhan bahan bakar untuk energi di Indonesia tiap tahunnya tercatat semakin meningkat seiring dengan peningkatan jumlah penduduk dan kemajuan industri. Di sisi lain, cadangan minyak nasional semakin lama semakin menurun. Untuk mengatasi krisis energi yang terjadi diperlukan suatu usaha untuk mencari sumbersumber energi alternatif baru yang lebih murah, berlimpah dan dapat diperbaharui. Energi alternatif yang saat ini banyak dikembangkan adalah biomassa (Haryadi, 2009) [1]. 
Negara kita merupakan Negara dengan wilayah pertanian dan perkebunan yang luas sehingga menghasilkan biomassa yang melimpah, beberapa diantaranya sekam padi, tempurung kelapa, tongkol jagung, dan limbah kayu. Limbah kayu sendiri memiliki jumlah yang sangat banyak jenisnya, contohnya limbah kayu Sengon, kayu Jati, kayu Mahoni, kayu Lamtoro dan sebagainya. Kayu-kayu tersebut biasanya digunakan sebagai bahan pengrajin maupun furniture. Kayu Sengon sendiri banyak terdapat di daerah Jawa Tengah terutama di Kabupaten Wonosobo (Kecamatan Kepil dan Kecamatan Sapuran) dan Temanggung (Kecamatan Pringsurat). Dewasa ini masyarakat hanya menggunakan limbah dari produksi kayu sengon tersebut untuk pembuatan pupuk kompos, namun dengan teknologi yang sudah maju dapat dilakukan pemanfaatan limbah kayu sengon tersebut untuk menghasilkan syngas dengan proses gasifikasi. Komposisi limbah pada kegiatan pemanenan kayu berupa serbuk gergaji sekitar 10,6\% dan pada industri kayu lapis sekitar 0,7\% [2].

Biomassa merupakan keseluruhan materi yang berasal dari makhluk hidup, termasuk bahan organik yang hidup maupun yang mati, baik di atas permukaan tanah maupun yang ada di bawah permukaan tanah. Potensi limbah biomassa terbesar adalah dari limbah kayu hutan, kemudian diikuti oleh limbah padi, jagung, ubi kayu, kelapa, kelapa sawit dan tebu. Secara umum bahan baku biomassa dibedakan menjadi dua jenis utama, yaitu pohon berkayu (woddy) dan rumput-rumputan (herbaceous). Saat ini material berkayu diperkirakan merupakan 50\% dari total potensial bioenergi sedangkan 20\% lainnya adalah jerami yang diperoleh dari hasil samping pertanian (Rochman, 2009)[3].

Salah satu biomassa yang dapat menggantikan energi alternatif yaitu serbuk gergaji kayu Mahoni. Komponen struktural serbuk gergaji kayu mahoni yaitu selulosa 47,26\%, hemiselulosa 27,37\%, holoselulosa 74,63\% dan lignin 25,82\% (Santoso, 2016)[4]. Kayu mahoni merupakan kayu asli Indonesia yang memiliki nama botani Swietenia sp. atau Swietenia Mahagoni dan memiliki nama dagang Mahoni. Kayu ini tersebar di Pulau Jawa. Kayu mahoni memiliki ciri-ciri yaitu keras berwarna cokelat muda kemerah-merahan atau kekuning-kuningan sampai coklat tua kemerahmerahan, dan lambat laun menjadi lebih tua, tekstur kayu sedikit halus dan permukaan kayunya sedikit licin. Kandungan selulosa pada kayu mahoni sebesar 46,8\%, lignin sebesar 26,9\%, abu 0,6\% dan silika sebesar 0,1\%. Jumlah zat selulosa mayoritas lebih dari 40\%, dan lignin kurang dari $34 \%$.

Perkembangan sumber energi biomassa sudah jauh berbeda dan mengalami banyak perubahan. Pembakaran adalah metode utama untuk mengubah biomassa menjadi energi, tetapi seiring dengan perkembangan ilmu dan teknologi telah mengubah aplikasi biomassa menjadi lebih modern. Proses gasifikasi merubah biomassa menjadi gas, pirolisis (merubah biomassa menjadi arang), penguraian anaerobik dan pembriketan adalah proses yang mampu mengubah wujud biomassa menjadi energi [5].

Prinsip gasifikasi biomassa dengan cara melakukan pembakaran secara tidak sempurna di dalam sebuah ruangan yang mampu menahan temperatur tinggi yang disebut gasifier. Agar pembakaran tidak sempurna dapat terjadi, maka udara dengan jumlah yang sedikit dari kebutuhan stokiometrik pembakaran dialirkan ke dalam reaktor untuk mensuplai kebutuhan oksigen menggunakan fan/blower. Proses pembakaran yang terjadi menyebabkan reaksi termo-kimia yang menghasilkan $\mathrm{CO}, \mathrm{H}_{2}$, dan gas metana $\left(\mathrm{CH}_{4}\right)$ (Tokan, Albertus M.A.E., 2011)[6]. Salah satu jenis gasifier yaitu Downdraft gasifier dimana gas hasil pembakaran dilewatkan pada bagian oksidasi dari pembakaran dengan cara ditarik mengalir ke bawah sehingga gas yang dihasilkan akan lebih bersih karena tar dan minyak akan terbakar sewaktu melewati bagian oksidasi dari pembakaran. (Anil Kr. Jain dan John R. Goss, 2003)[7]. Gasifikasi jenis downdraft bisa menggunakan berbagai jenis biomassa [8] [9]. Dari uraian pendahuluan diatas, penelitian yang dilakukan yaitu gasifikasi biomassa serbuk gergaji kayu mahoni.

\section{Metode Penelitian}

Pada penelitian ini digunakan peralatan untuk proses gasifikasi berupa unit gasifikasi yang dilengkapi dengan thermocouple untuk mengukur suhu selama proses gasifikasi. Unit gasifikasi yang digunakan pada penelitian ini terdapat pada gambar 1 . 


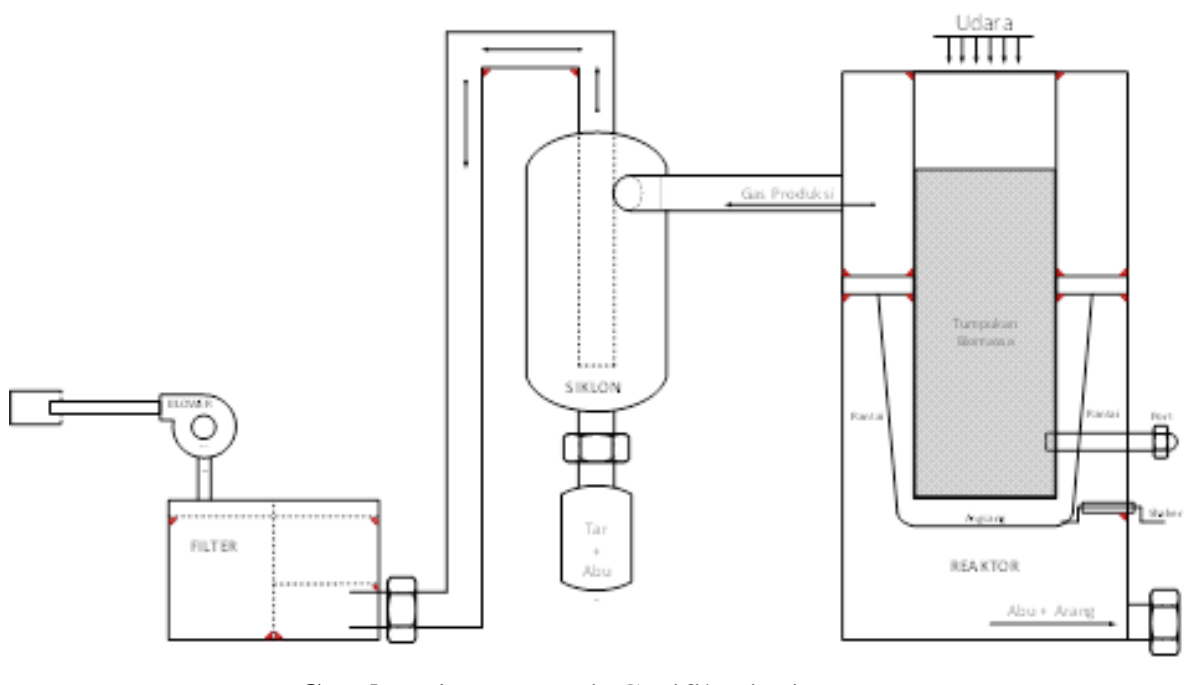

Gambar 1. Unit Gasifikasi Biomassa

Metode yang digunakan dalam penelitian ini adalah batch feed system yaitu metode dengan memasukkan sejumlah biomassa ke dalam reaktor kemudian disulut api. Bahan baku yang digunakan pada penelitian ini menggunakan serbuk gergaji kayu mahoni yang berasal dari salah satu pengrajin furnitur di daerah Bantul. Pada proses awal serbuk kayu mahoni dijemur di bawah terik sinar matahari selama \pm 4 jam untuk mengurangi kadar air. Percobaan dilakukan setelah seluruh peralatan gasifikasi dan alat ukur yang digunakan telah dipastikan berfungsi dengan baik. Adapun diagram alir penelitian terdapat pada gambar 2. berikut:

Mempersiapkan unit gasifier yang dilengkapi thermocouple dan blower

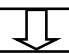

Memberi air pada bagian bawah gasifier sebagai seal

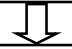

Memasukkan serbuk gergaji kayu mahoni yang sudah ditimbang ke dalam gasifier

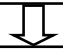

Menjalankan blower untuk mengalirkan udara pembakaran ke dalam gasifier<smiles>[Li]</smiles>

Menyalakan biomassa melalui lubang penyalaan

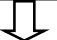

Mengukur perubahan suhu gasifikasi menggunakan termocouple

ए1

Mengukur waktu keluaran gas hasil gasifikasi yang terbakar

I1

Mengambil sampel gas hasil gasifikasi dan disimpan di dalam vacuum tube

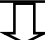

Menimbang tar dan abu yang dihasilkan dari proses gasifikasi

Gambar 2. Diagram alir penelitian gasifikasi serbuk gergaji kayu mahoni 


\section{Hasil dan Pembahasan}

Dapat diketahui menurut Kitani and Hall (1989) [10] tersebut pada bahan baku serbuk kayu memiliki kadar air dengan rentang sekitar 25-55\%. Pada serbuk kayu yang kami gunakan memiliki kandungan air dengan kadar sekitar 29,6\%. Hal ini menandakan bahwa bahan serbuk kayu mahoni dapat digunakan untuk biomassa.

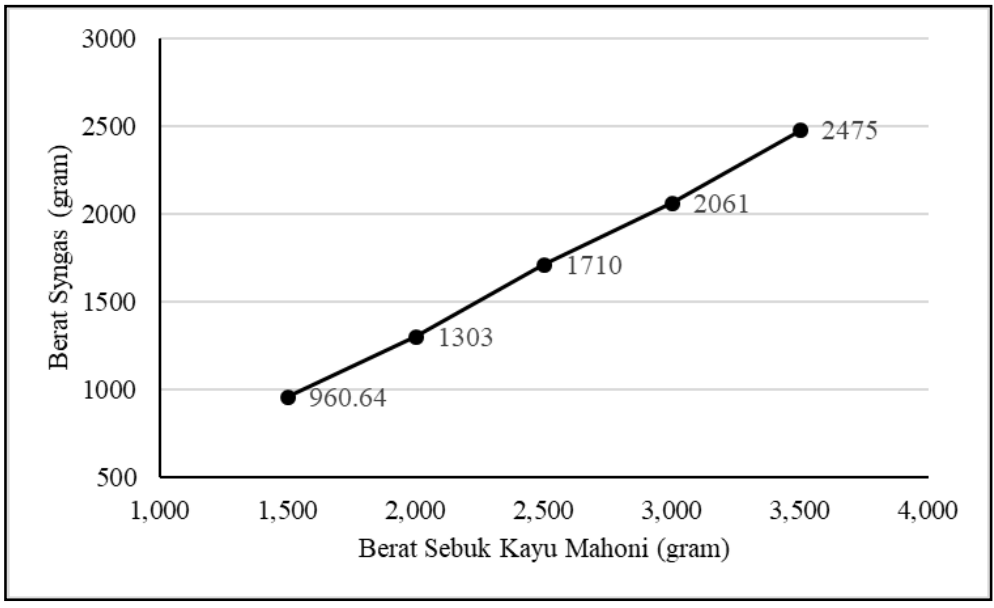

Gambar 3. Grafik berat serbuk kayu mahoni terhadap yield syngas

Dari Gambar 3 tentang pengaruh berat serbuk kayu mahoni terhadap yield syngas dengan variabel berat 1,500 gram; 2,000 gram; 2,500 gram; 3,000 gram; dan 3,500 gram menghasilkan berat syngas berturut-turut, yaitu $64,04 \% ; 65,15 \% ; 68,40 \% ; 68,70 \%$; dan $70,71 \%$. Grafik tersebut menunjukkan bahwa semakin banyak serbuk kayu mahoni yang diumpankan, maka semakin banyak syngas yang dihasilkan.

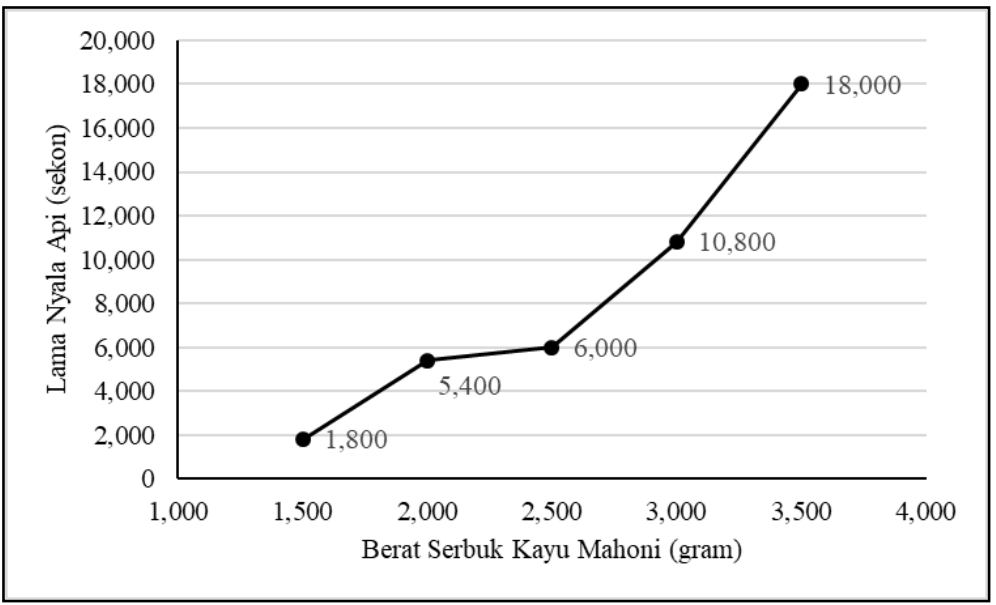

Gambar 4. Grafik berat serbuk kayu mahoni terhadap waktu pengeluaran syngas

Dari gambar 4 tentang pengaruh berat serbuk kayu mahoni terhadap waktu pengeluaran syngas dengan variabel berat 1,500 gram; 2,000 gram; 2,500 gram; 3,000 gram; dan 3,500 gram menghasilkan syngas dengan lama pengeluaran berturut-turut, yaitu $1.800 \mathrm{~s} ; 5.400 \mathrm{~s} ; 6.000 \mathrm{~s} ; 10.800$ $\mathrm{s}$; dan $18.000 \mathrm{~s}$. Grafik tersebut menunjukkan bahwa dengan berat serbuk kayu mahoni 3.500 gram menghasilkan syngas dengan pengeluaran terlama yaitu selama $18.000 \mathrm{~s}$. Sedangkan untuk waktu pengeluaran syngas tercepat dengan berat 1.500 gram yaitu selama $1.800 \mathrm{~s}$. 


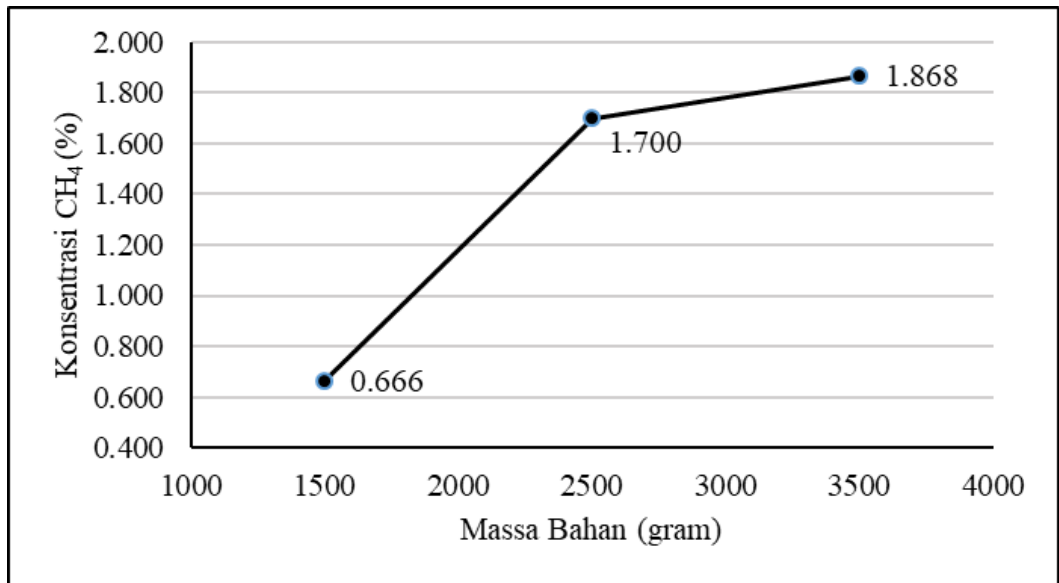

Gambar 5. Grafik berat serbuk kayu mahoni terhadap konsentrasi $\mathrm{CH}_{4}$ pada hasil analisis

Dari gambar 5. Didapatkan hasil analisis $\mathrm{CH}_{4}$ pada massa bahan 1,5 kg, 2,5 kg, dan 3,5 kg. Dari data tersebut dapat diketahui bahwa pada sampel $1,5 \mathrm{~kg}$ memiliki konsentrasi terkecil sebesar $0,666 \%$, sedangkan pada sampel 3,5 kg memiliki konsentrasi tertinggi dalam analisis $\mathrm{CH}_{4}$ sebesar $1,868 \%$.

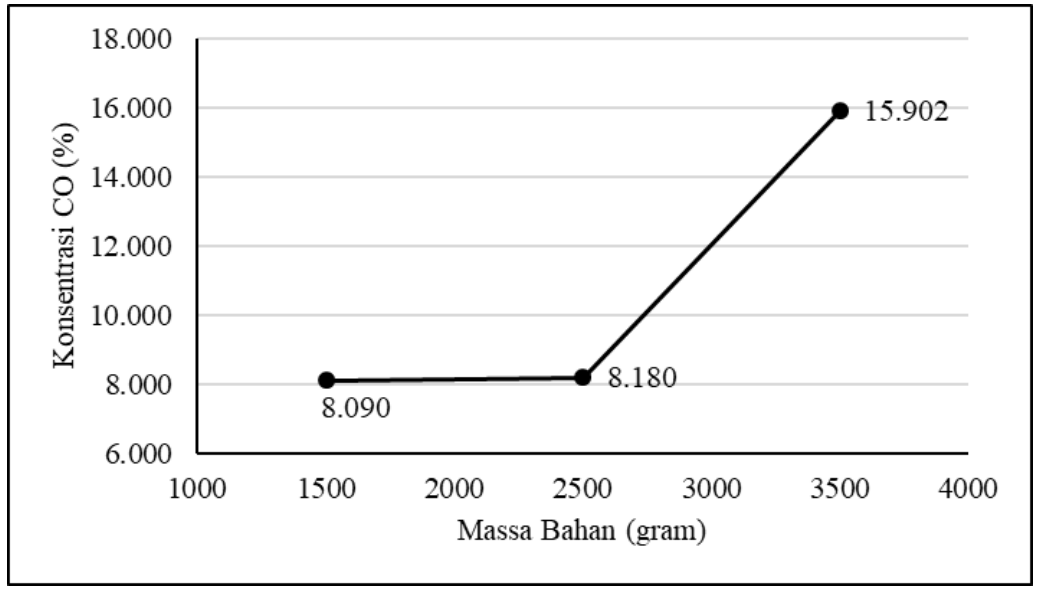

Gambar 6. Grafik berat serbuk kayu mahoni terhadap konsentrasi CO pada hasil analisis

Dari Gambar 6. Didapatkan hasil analisis CO pada massa bahan 1,5 kg, 2,5 kg, dan 3,5 kg. CO memiliki peran terbesar dalam menghasilkan gas mampu bakar atau syngas. Dari data tersebut dapat diketahui bahwa pada sampel 3,5 kg memiliki konsentrasi terbesar sebesar 15,902\%, sedangkan pada sampel 2,5 kg yang memiliki konsentrasi terkecil dalam analisis CO sebesar 8,090\%.

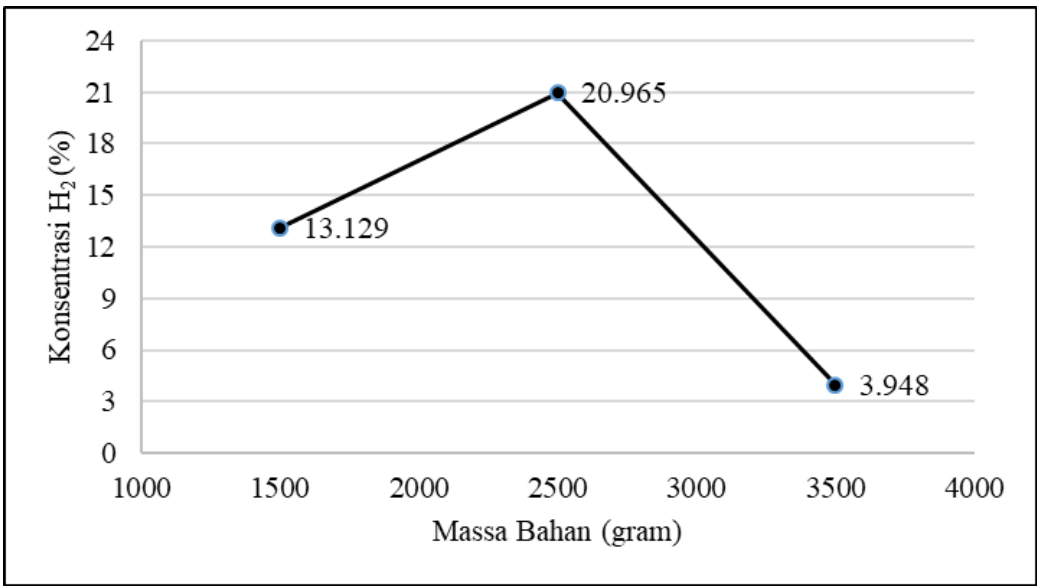

Gambar 7. Grafik berat serbuk kayu mahoni terhadap konsentrasi $\mathrm{H}_{2}$ pada hasil analisis 
Dari gambar 7. Didapatkan hasil analisis $\mathrm{H}_{2}$ pada massa bahan $1,5 \mathrm{~kg}, 2,5 \mathrm{~kg}$, dan 3,5 kg. Dari data tersebut dapat diketahui bahwa pada sampel $2,5 \mathrm{~kg}$ memiliki konsentrasi terbesar sebesar $20,965 \%$, sedangkan pada sampel 3,5 kg memiliki konsentrasi terendah dalam analisis $\mathrm{H}_{2}$ sebesar $3,948 \%$. Hal ini menandakan bahan yang digunakan pada sampel 3,5 $\mathrm{kg}$ memiliki kandungan air yang relatif lebih rendah dibandingkan sampel $1,5 \mathrm{~kg}$ dan $2,5 \mathrm{~kg}$.

\section{Kesimpulan}

Kesimpulan yang didapatkan berdasarkan penelitian yang telah dilakukan bahwa gasifikasi serbuk gergaji kayu mahoni dapat menghasilkan bahan bakar gas. Dimana semakin banyak biomassa yang digasifikasi akan meningkatkan jumlah gas yang dihasilkan untuk menjadi bahan bakar. Rata-rata kandungan gas hasil gasifikasi $1,41 \% \mathrm{CH}_{4}, 10,72 \% \mathrm{CO}$ dan $12,68 \% \mathrm{H}_{2}$.

\section{Ucapan Terimakasih}

Terimakasih saya ucapkan kepada putri ayu sulastri dan destya ardiyati yang telah membantu dalam pengambilan data penelitian. Serta bapak agus aktawan yang sudah bersedia menyediakan alat penelitian untuk menunjang penelitian gasifikasi biomassa ini.

\section{Daftar Pustaka}

[1] Haryadi, H. 2009. Pengenalan Bahan Biomass. Makalah Pelatihan Biomass Energi. Baristand Industri Surabaya. Surabaya.

[2] Purwanto D, Samet, Mahfuz, dan Sakiman, 1994. "Pemanfaatan Limbah Industri Kayu lapis untuk Papan Partikel Buatan secara Laminasi”, DIP Proyek Penelitian dan Pengembangan Industri, Badan Penelitian dan Pengembangan Industri, Departemen Perindustrian, Banjar Baru.

[3] Rochman, R. 2009. "Biomass To Liquid (kayu dan rerumputan)".

[4] Karlinasari, L., Rahmawati, M. and Mardikanto, T.R., 2010. Pengaruh pengawetan kayu terhadap kecepatan gelombang ultrasonik dan sifat mekanis lentur serta tekan sejajar serat kayu Acacia mangium Willd. Journal of Civil Engineering, 17(3), pp.163-170.

[5] Saputro, D. D. and Widayat, W., 2007. a, Biomassa sebagai sumber energi alternatif terbarukan di Indonesia. Jurnal Profesional, 5(2), pp.705-716.

[6] Tokan, A., 2011. "Uji efisiensi gasifier UB-03-01". Laporan Penelitian, Jurusan Fisika, FMIPA. Universitas Brawijaya, Malang.

[7] Anil Kr. Jain dan John R. Goss. 2003."Determination Of Reactor Scalling Factor for Throatless Risk Husk Gasifier,” International Journal Biomass \& Bioenergy. Vol. 18, No. 3:249-256.

[8] Aktawan, A., Prasetya, A. and Wilopo, W., 2015. Study of characteristics of gasification process of various biomass in a downdraft gasifier. ASEAN Journal of Systems Engineering, 3(1).

[9] Maryudi, M., Aktawan, A. and Salamah, S., 2018. Conversion of Biomass of Bagasse to Syngas Through Downdraft Gasification. Jurnal Bahan Alam Terbarukan, 7(1), pp.28-33.

[10] Kitani, O., \& Hall, C. W. (1989). "Biomass handbook". New York: Gordon and Breach Science Publishers. 